\title{
The People Living With HIV Stigma Index: Dominican Republic
}

Red Dominicana de Personas que Viven con VIH/SIDA

Alianza Solidaria para la Lucha Contra el VIH y SIDA

Population Council

Follow this and additional works at: https://knowledgecommons.popcouncil.org/departments_sbsr-hiv

Part of the International Public Health Commons, and the Social and Behavioral Sciences Commons How does access to this work benefit you? Let us know!

\section{Recommended Citation}

Red Dominicana de Personas que Viven con VIH/SIDA, Alianza Solidaria para la Lucha Contra el VIH y SIDA, and Population Council. 2019. "The People Living With HIV Stigma Index: Dominican Republic." Washington, DC: USAID | Project SOAR. 


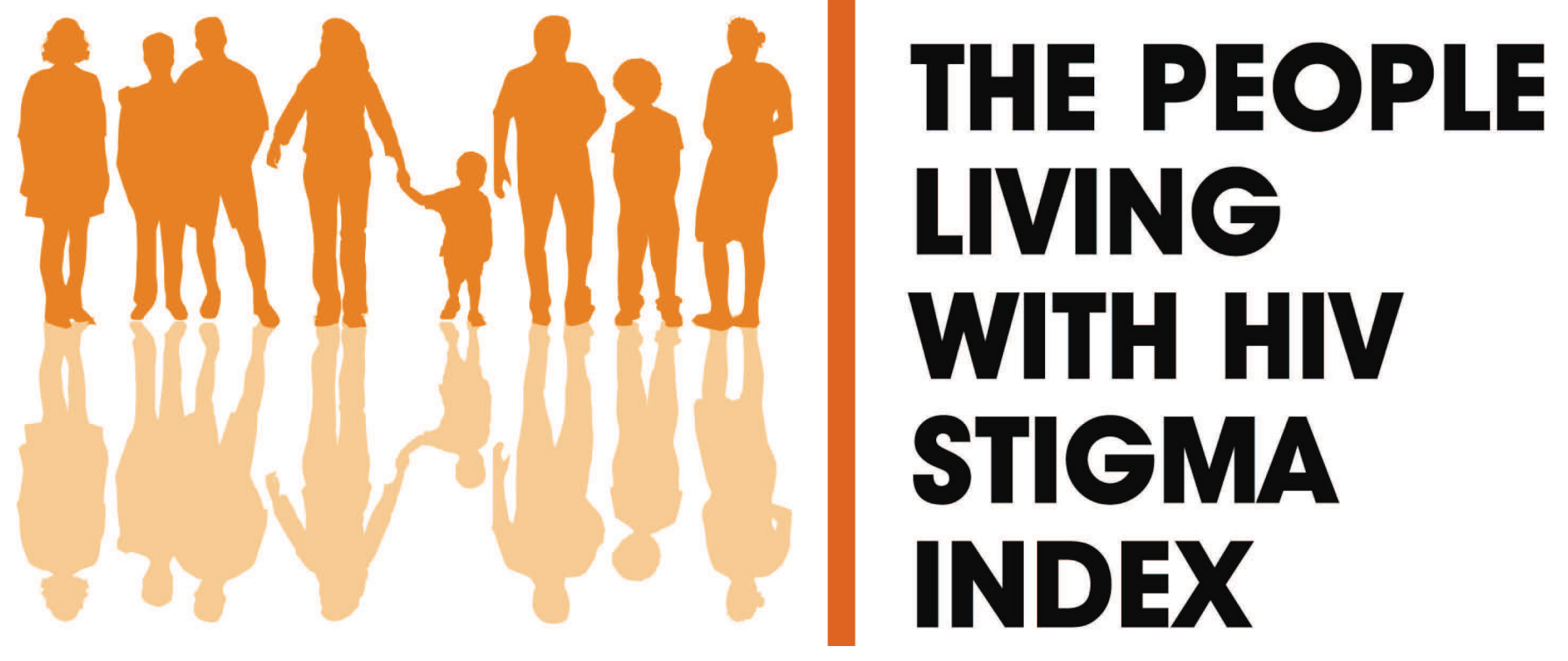

\section{Dominican} Republic

\section{November 2019}




\title{
Dominican Republic
}

\author{
Prepared by \\ Project SOAR \\ Population Council \\ 4301 Connecticut Ave, NW, Suite 280 \\ Washington, D.C. 20008 USA \\ Tel: +1202 2379400 \\ Fax: +1 2022378410 \\ projsoar.org
}

In 2017, the USAID/Dominican Republic Mission supported Project SOAR to field the People Living with HIV Stigma Index 2.0 in the Dominican Republic. The Population Council provided technical support to two in-country PLHIV organizations to conduct this activity: Alianza Solidaria para la Lucha Contra el VIH y SIDA (ASOLSIDA) and Red Dominicana de Personas que Viven con VIH/SIDA (REDOVIH).

Project SOAR (Cooperative Agreement AID-OAA-A-14-00060) is made possible by the generous support of the American people through the United States President's Emergency Plan for AIDS Relief and the United States Agency for International Development (USAID). The contents of this guidance document are the sole responsibility of Project SOAR and the Population Council and do not necessarily reflect the views of USAID or the United States Government.

Through operations research, Project SOAR will determine how best to address challenges and gaps that remain in the delivery of HIV and AIDS care and support, treatment, and prevention services. Project SOAR will produce a large, multifaceted body of highquality evidence to guide the planning and implementation of HIV and AIDS programs and policies. Led by the Population Council, Project SOAR is implemented in collaboration with Avenir Health, Elizabeth Glaser Pediatric AIDS Foundation, Johns Hopkins University, Palladium, and The University of North Carolina.

The Population Council confronts critical health and development issues-from stopping the spread of HIV to improving reproductive health and ensuring that young people lead full and productive lives. Through biomedical, social science and public health research in about 50 countries, the Council works with our partners to deliver solutions that lead to more effective policies, programs, and technologies to improve lives worldwide. Established in 1952 and headquartered in New York, the Council is a nongovernmental, nonprofit organization with an international board of trustees.

Published in November 2019. (C2019 The Population Council, Inc.

Some rights reserved: This document may be freely shared, copied, translated, reviewed and distributed, in part or in whole, but not for sale or use in conjunction with commercial purposes. Only authorised translation, adaption and reprints may bear the emblems of GNP+, the international partnership, USAID, PEPFAR, or Population Council.

Suggested citation: Red Dominicana de Personas que Viven con VIH/SIDA, Alianza Solidaria para la Lucha Contra el VIH y SIDA, and Population Council. 2019. People Living with HIV Stigma Index 2.0 Dominican Republic Country Assessment. Washington, DC: USAID | Project SOAR.
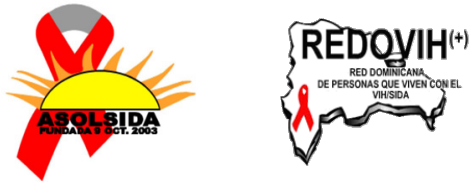


\section{Dominican Republic}




\section{ACRONYMS}

ASOLSIDA Alianza Solidaria para la Lucha Contra el VIH y SIDA

CONAVIHSIDA National Council on HIV and AIDS

DR Dominican Republic

FSW Female sex worker

GNP+ Global Network of People Living with HIV

MSM Men who have sex with men

PEPFAR United States President's Emergency Plan for AIDS Relief

PLHIV People living with HIV

REDOVIH Red Dominicana de Personas de Personas que Viven con VIH/SIDA

UNAIDS Joint United Nations Programme on HIV/AIDS

USAID United States Agency for International Development

WSW Women who have sex with women 


\section{ACKNOWLEDGMENTS}

ASOLSIDA, REDOVIH, and the Population Council would like to thank the many supporters, staff, and community members who made this study possible. Special thanks to Yordana Dolores and Bethania Betances for their ongoing technical support throughout the study, and to Rosalía Carvajal for her overall coordination efforts. In addition, we are grateful to our multisectoral stakeholders who provided guidance, feedback, and advice on Stigma Index implementation and interpretation of results.

Most importantly we would like to acknowledge the invaluable role of people living with HIV who participated in this study for their time and sharing their stories. We trust that these findings will contribute to improving the health and quality of their lives and that of people with HIV in general. 


\section{TABLE OF CONTENTS}

ACRONYMS ................................................................................................. if

ACKNOWLEDGMENTS.............................................................................. iii

EXECUTIVE SUMMARY ..................................................................... 1

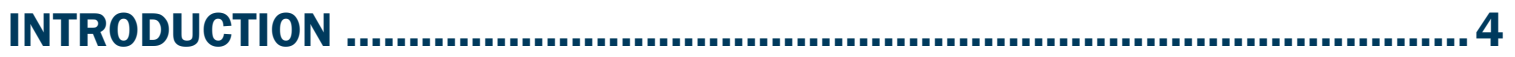

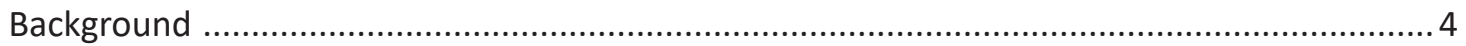

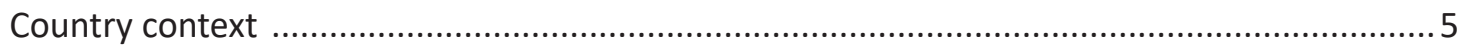

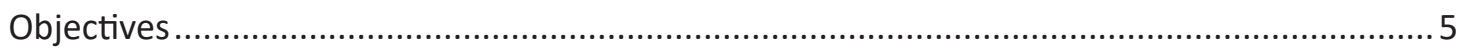

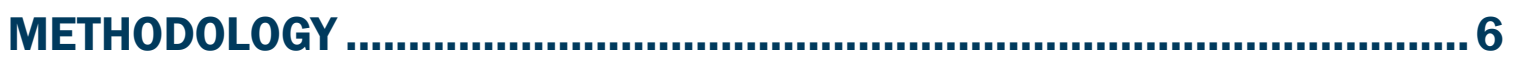

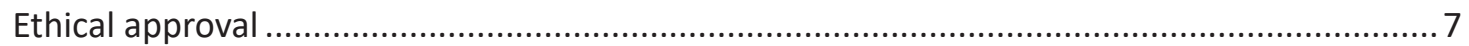

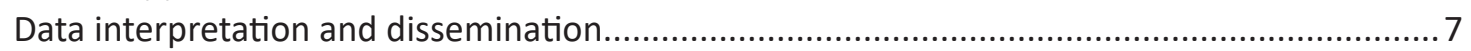

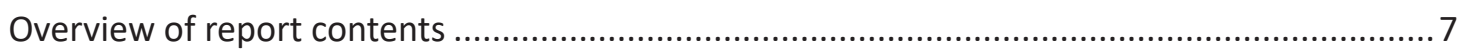

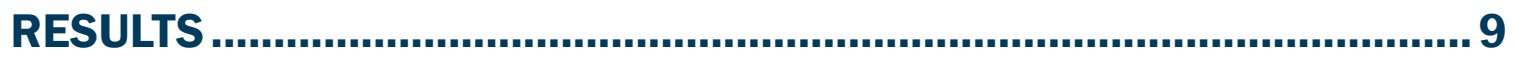

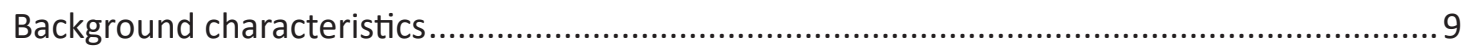

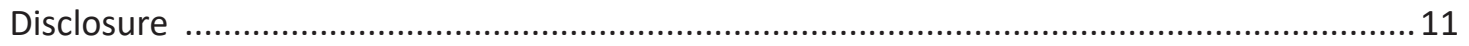

Experiences with HIV-related discrimination.......................................................... 12

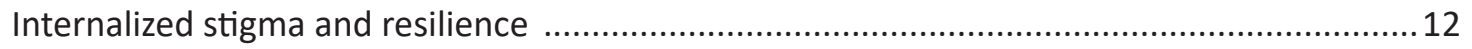

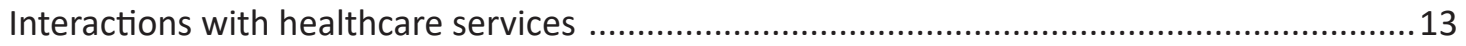

Human rights and effecting change ..................................................................... 18

Stigma and discrimination experienced for reasons other than HIV status .........................18

IMPLICATIONS AND RECOMMENDATIONS ..........................................21

LIMITATIONS AND CHALLENGES..........................................................24

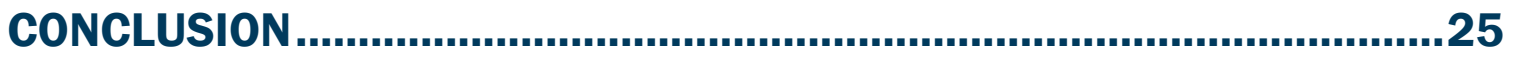

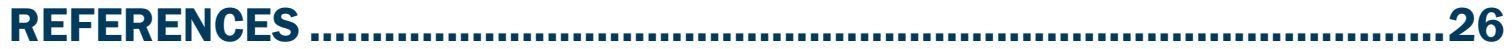

DISCLAIMER ............................................................................................28 


\section{Dominican Republic}

\section{EXECUTIVE SUMMARY}

People living with HIV (PLHIV) often experience stigma and discrimination that can affect their well-being in significant ways. HIV-related discrimination is not only a human rights violation, but also impedes people's ability to access HIV testing, care, and treatment. The People Living with HIV Stigma Index was developed in 2008 by the Global Network of People Living with HIV (GNP+), the International Community of Women Living with HIV, International Planned Parenthood Federation, and UNAIDS. The Stigma Index is a survey instrument used to highlight stigma and discrimination experienced by PLHIV, who both serve as interviewers as well as respondents. In 2016-17, the United States President's Emergency Plan for AID Relief (PEPFAR) and the United States Agency for International Development (USAID) supported the Population Council-led research consortium, Project SOAR, to update the Stigma Index to reflect changes in the global HIV response in the past decade. In 2017, the USAID/Dominican Republic (DR) Mission supported Project SOAR to field the revised instrument (Stigma Index 2.0) in the DR. The Council provided technical support to two in-country PLHIV organizations to conduct this activity: Alianza Solidaria para la Lucha Contra el VIH y SIDA (ASOLSIDA) and Red Dominicana de Personas que Viven con VIH/SIDA (REDOVIH).

PLHIV interviewers conducted the survey among 891 participants in La Altagracia, Barahona, Puerto Plata, La Romana, Santiago, and Santo Domingo provinces. Included in the study population were 216 female sex workers (FSWs), 154 men who have sex with men (MSM), and 90 PLHIV of Haitian descent. Eligible respondents were 18 or over, able to conduct the interview in Spanish or Haitian Creole, and had been diagnosed at least one year ago. Potential participants were recruited through PLHIV networks, at service delivery sites for PLHIV, and through networks of key populations.

Most had disclosed their status to spouses/partners (52 percent) or other relatives (67 percent), but many reported that it has not gotten easier over time to disclose. The most commonly reported manifestation of HIV-related discrimination was being aware of family members (27 percent) and non-family members (36 percent) making discriminatory remarks due to their HIV status. Thirteen percent had been refused employment or lost income because of their status, rising to 17 percent among FSWs.

Nearly all (98 percent) were currently receiving HIV treatment, but only 56 percent had been told that they had an undetectable viral load in the past 12 months. Among participants of Haitian descent, this dropped to 33 percent.

Over half reported feeling down, depressed, or hopeless in the past two weeks, and 42 percent said they were not able to stop or control worrying during that time period. FSWs and participants of Haitian descent were particularly burdened by depression, with more than 60 percent reporting that they had felt down, depressed, or hopeless in the past two weeks. 


\section{Stigma Index}

Discriminatory experiences in healthcare services were more frequently reported in non-HIVrelated services. For example, 14 percent had had staff at non-HIV-related services talk badly to them due to their status, compared to 7 percent in HIV-specific services. Similarly, 12 percent had non-HIV-related services staff disclose their status without their consent, compared to 7 percent in HIV-specific services.

The most commonly reported rights abuse reported by participants was being forced to get tested for HIV or disclose their status in order to apply for a job or pension plan (8 percent). Although two-thirds of the overall study population knew there were laws in the country to protect PLHIV from discrimination, just 40 percent of the Haitian-origin population was aware of such protections.

At a dissemination meeting convened by ASOLSIDA and REDOVIH in Santo Domingo on 6 June 2019, community members made the following conclusions and recommendations:

\section{PLHIV need education about their rights regarding employment discrimination.}

Both employers and PLHIV needed to be sensitized about the labor rights of PLHIV. This need is particularly salient among those of Haitian origin, who exhibited lower awareness of the existence of laws that protect PLHIV rights, and were of lower economic status.

\section{Disclosure is an ongoing challenge, particularly among MSM and those of Haitian descent.}

Clinical and social services need to support disclosure, particularly for marginalized communities. In addition, public education campaigns are necessary to increase knowledge in the general population about what HIV is, and how it is and is not transmitted. Such efforts will help to confront and mitigate HIV-related stigma and facilitate disclosure.

\section{Lack of awareness of one's viral load highlights the need for improved counseling and treatment literacy.}

Providers need to counsel PLHIV to improve treatment literacy, ensure that PLHIV understand what viral suppression means, how risk of sexual transmission of HIV is eliminated when viral suppression is achieved, and that it is important to adhere to treatment even when virally suppressed. 


\section{Dominican Republic}

\section{Mental health issues require specialized psychosocial services.}

Counseling and support for PLHIV should include strengthened psychosocial services, or referral to such specialized mental health care, when necessary.

\section{Healthcare providers and staff need education and sensitization to reduce stigma and discrimination, particularly in non-HIV-services.}

Providers across specialties need education about PLHIV rights and how to provide respectful care. In addition, PLHIV need education about their rights, and there must be mechanisms to anonymously report abuses experienced in healthcare settings. Evidence-based interventions to reduce provider stigma and discrimination should be implemented to improve PLHIV experiences in health care settings.

\section{Peer education and community mobilization should focus on improving awareness of laws supporting PLHIV rights.}

PLHIV advocates and community members stressed the need to fortify peer education and community mobilization efforts to improve awareness of existing laws in the country protecting the rights of PLHIV, particularly among those of Haitian origin.

\section{Different communities have diverse needs, which require customized responses.}

Employment-related discrimination was reported most frequently among FSWs, for whom disclosure of HIV status could mean losing clients, for instance. Although not identified as a key population in most HIV programs in the DR, 11 percent of respondents used drugs, underscoring the need to consider their unique needs in the HIV response. 


\section{Stigma Index}

\section{INTRODUCTION}

\section{Background}

People living with HIV (PLHIV) often experience stigma and discrimination that can affect their well-being in significant ways. HIV-related discrimination is not only a human rights violation, but also has an impact on people's ability to access HIV testing, care, and treatment. The United Nations' 2016 High-Level Meeting on Ending AIDS included "elimination of HIV-related discrimination" as one of three critical targets to achieve by 2020, along with reducing the number of PLHIV and people dying from AIDS-related causes to under half a million people.

The People Living with HIV Stigma Index was developed in 2008 by the Global Network of People Living with HIV (GNP+), the International Community of Women Living with HIV, International Planned Parenthood Federation, and UNAIDS. The Stigma Index is a survey instrument used to highlight stigma and discrimination experienced by PLHIV. PLHIV lead the data collection and results dissemination, ensuring that their voices are heard throughout the process. The survey itself includes a combination of open-ended and closed-ended questions, and its administration can take about an hour. Developed and administered by and for PLHIV, the Stigma Index is not merely a measurement tool; its implementation is intended to be an empowering experience for PLHIV, upholding the Greater Involvement of People Living with HIV and AIDS principle. Developed in 2008, more than 2,000 PLHIV have since been trained as interviewers; 100,000 PLHIV have been interviewed from 90 countries; and the survey has been translated into 54 languages. In 2016-17, the United States President's Emergency Plan for AID Relief (PEPFAR) and the United States Agency for International Development (USAID) supported the Population Council-led research consortium, Project SOAR, to update the Stigma Index, to reflect changes in the global HIV response in the past decade. The new version (Stigma Index 2.0) now has an increased focus on PLHIV's experiences accessing HIV services; using and adhering to antiretroviral treatment; mental health and resilience; and stigma within health care settings. The updated tool also pays more attention to compounded stigma that PLHIV may experience for being sexual minorities or other marginalized communities (such as sex workers or drug users).

In 2017, the USAID/Dominican Republic (DR) Mission supported Project SOAR to field the revised instrument (Stigma Index 2.0) in the DR. The Council provided technical support to two in-country PLHIV organizations to conduct this activity: Alianza Solidaria para la Lucha Contra el VIH y SIDA (ASOLSIDA) and Red Dominicana de Personas que Viven con VIH/SIDA (REDOVIH). ASOLSIDA and REDOVIH led the implementation of the original Stigma Index among 1,000 PLHIV in 2008, which documented widespread experiences with discrimination and rights violations, as well as high prevalence of internal stigma. For example, in the previous 12 months, one-fifth had been forced to change homes or had a property rental denied to them, among whom 42 percent stated that this denial was due to their HIV status. Among women who participated in 


\section{Dominican Republic}

the original Stigma Index in 2008, 23 percent had been advised by a health care professional that they should not have children, and 11 percent had been coerced by a health care professional to get sterilized. About one-third had felt ashamed (31 percent) or guilty (30 percent) in the past 12 months (Cacéres 2009).

More recently, in 2017, the National Council on HIV and AIDS (CONAVIHSIDA) conducted a study that examined the attitudes of health care providers in the DR toward PLHIV. Nearly half of providers (48 percent) agreed with the statement "people get infected by HIV because they engage in irresponsible behaviors," and 23 percent agreed that women who are living with HIV should not be allowed to have babies. In addition, 56 percent said that they prefer not to provide services to men who have sex with men because they engage in immoral conduct. (Valdez, Barillas, Cepeda, and Ledesma 2017)

To complement the CONAVIHSIDA study and provide updated evidence on stigma and discrimination from the perspective of PLHIV, ASOLSIDA and REDOVIH led implementation of Stigma Index 2.0 in the DR. PLHIV interviewers documented the experiences of PLHIV in the four provinces in which PEPFAR supports HIV service delivery-La Romana, Puerto Plata, Santiago, and Santo Domingo-in addition to provinces that ASOLSIDA and REDOVIH identified as having most affected communities (La Altagracia and Barahona).

\section{Country context}

Adult HIV prevalence in the DR is 0.8 percent, ranging from a low of 0.3 percent in Health Region I (Peravia, San Cristóbal, and San José de Ocoa) to a high of 1.8 percent in Health Region VII (Dajabón, Monte Cristi, Santiago Rodríquez, and Valverde). Prevalence is slightly higher among men compared to women (0.9 percent versus 0.7 percent) (Centro de Estudios Sociales y Demográficos \& ICF International 2014). In addition, female sex workers (FSWs) and men who have sex with men (MSM) are disproportionately affected. Among FSWs, HIV prevalence is estimated to be between 1.7 percent and 6.3 percent, and among MSM, prevalence ranges from 3.9 percent to 6.9 percent. An estimated 48 percent of new HIV diagnoses are among people of Haitian origin, with an estimated prevalence of 4.9 percent to 6.6 percent. (Valdez et al. 2017)

\section{Objectives}

The objective of this study was to document the experiences of PLHIV regarding HIV-related stigma and discrimination. In addition, through the process of leading the implementation of Stigma Index 2.0, the study team aimed to facilitate an empowering experience for PLHIV in the DR. 


\section{Stigma Index}

\section{METHODOLOGY}

The study team aimed to capture the experiences of priority communities living with HIV, identified by ASOLSIDA, REDOVIH, and USAID/DR as PLHIV who were MSM, FSWs, and people of Haitian origin. In addition, we sought to include PLHIV from geographic areas in which service delivery sites were supported by PEPFAR. To achieve these twin aims, the study team aimed to attain a sample size of 1,000 (i.e., the same sample size as the 2008 implementation of the Stigma Index in the DR). In order to ensure inclusion of the key PLHIV subgroups of interest, the study team planned to include at least 200 MSM, 200 FSWs, and 100 PLHIV of Haitian origin among the 1,000 participants recruited through purposive, non-probability-based sampling. Eligibility criteria for participation were as follows:

\section{Inclusion criteria}

- 18 years of age or older.

- Self-reported living with HIV for at least one year.

- Mentally sound and capable of giving consent.

- Provided informed consent to participate in the study.

- Speaks Haitian Creole or Spanish.

\section{Exclusion criteria}

- Less than 18 years old.

- Self-reported living with HIV for less than one year.

- Demonstrates mental incapacity, under the influence of substances, or any other illness preventing comprehension of the study procedures and informed consent.

- Does NOT speak any of the languages in which the study is conducted.

- Has already participated in the study.

Recruitment efforts and interviewer assignments were distributed across the geographic areas surrounding the facilities and mobile clinics listed in Table 1.

Table 1 Study areas

\begin{tabular}{|c|c|}
\hline PROVINCE & SERVICE DELIVERY SITES \\
\hline La Altagracia & $\begin{array}{l}\text { Hospital Nuestra Señora de la } \\
\text { Altagracia }\end{array}$ \\
\hline Barahona & $\begin{array}{l}\text { Hospital Regional Universitario } \\
\text { Jaime Mota }\end{array}$ \\
\hline \multirow[t]{3}{*}{ Puerto Plata } & $\begin{array}{l}\text { Centro de Promoción y } \\
\text { Solidaridad Humana (CEPROSH)* }\end{array}$ \\
\hline & Mobile clinic* \\
\hline & Hospital Ricardo Limardo* \\
\hline \multirow[t]{2}{*}{ La Romana } & Clínica de Familia* \\
\hline & $\begin{array}{l}\text { Hospital Provincial Franciso A. } \\
\text { Gonzalvo* }\end{array}$ \\
\hline \multirow[t]{3}{*}{ Santiago } & Centro de Salud Juan XXIII* \\
\hline & Mobile clinic* \\
\hline & $\begin{array}{l}\text { Hospital Regional Universitario } \\
\text { José María Cabral y Báez }\end{array}$ \\
\hline \multirow[t]{4}{*}{$\begin{array}{l}\text { Santo } \\
\text { Domingo }\end{array}$} & $\begin{array}{l}\text { Centro de Orientación Integral } \\
\text { (COIN)* }\end{array}$ \\
\hline & Centro Sanitario* \\
\hline & $\begin{array}{l}\text { Instituto Dominicano de Estudios } \\
\text { Virológicos (IDEV)* }\end{array}$ \\
\hline & Hospital Lotes y Servicios* \\
\hline
\end{tabular}

*PEPFAR-supported 


\section{Dominican Republic}

Consistent with the methodology employed in the 2008 Stigma Index implementation in the DR, participants were identified through a combination of peer-to-peer recruitment through existing PLHIV support groups and service delivery sites, as well as through existing local PLHIV networks and nongovernmental organizations, or service delivery organizations for specific populations (such as FSWs or people of Haitian descent). In addition to this "snowball recruitment" of peers, the study team also conducted venue-based recruitment at clinics, PLHIV service organizations, and community-based organizations that the target populations frequented during certain days and times to receive HIV-related treatment, care, or social support.

PLHIV interviewers trained by ASOLSIDA and REDOVIH contacted participants in person or by phone, briefly described the study, and set a time and place to conduct the interview. Interviewers invited participants to meet at a private location to conduct the survey, ensuring that they had visual and auditory privacy. Interview sites were offices of PLHIV networks, or private spaces at or near facilities that provide HIV services. Upon completing the informed consent process, the interviewer administered the survey. Participant responses were recorded on tablets using the electronic data collection application Open Data Kit. GNP+ provided the study team with a Spanish translation of Stigma Index 2.0, and the survey was conducted in that language. For those participants who preferred to speak in Haitian Creole, bilingual interviewers spontaneously translated the survey aloud during the interview. The interview lasted approximately one hour.

\section{Ethical approval}

The study protocol was approved by two ethical review committees: the institutional review board of the Population Council (New York), and the Consejo Nacional de Bioética en Salud (CONABIOS) (Dominican Republic).

\section{Data interpretation and dissemination}

After data collection was completed, the study team and research advisory committeeincluding community members, ASOLSIDA, REDOVIH, UNAIDS, and the Population Councilconvened a data interpretation meeting to review and discuss preliminary analyses, and identify additional questions to explore through subsequent analyses. The study team also identified key study findings and recommendations to mitigate HIV-related stigma affecting priority populations in the country, all of which were shared at a dissemination meeting held in Santo Domingo on 6 June 2019. In attendance at this highly participatory event were study interviewers, community members, healthcare providers, donors, and policymakers. 


\section{Stigma Index}

\section{Overview of report contents}

This report contains descriptive statistics for the prevalence of experiences of HIV-related stigma and discrimination reported by participants. In the following sections, findings are organized in the same order that content areas are covered in the Stigma Index 2.0 survey. We present aggregated findings for the entire study population, with text boxes highlighting selected notable findings specific to subcommunities of interest (i.e., MSM, FSWs, and those of Haitian origin). Lastly, we include recommendations shared at a dissemination meeting convened by ASOLSIDA and REDOVIH in Santo Domingo on 6 June 2019. 


\section{Dominican Republic}

\section{RESULTS}

\section{Background characteristics}

Between November 2018 and January 2019, interviewers conducted surveys with 891 eligible participants who had learned their HIV status more than one year ago.

\section{Sociodemographic and HIV-related characteristics}

The participants were interviewed in the provinces of La Altagracia (6 percent), Barahona (5 percent), Puerto Plata (11 percent), Santiago (14 percent), La Romana (20 percent), and Santo Domingo (43 percent) (Data not shown).

Thirty-two percent self-identified as a member of a racial, ethnic, or religious minority. Ten percent stated that they were migrant workers, and 7 percent reported that they were living with a disability (other than HIV).

A small number of participants reported that they were members of an indigenous/aboriginal group (0.4 percent), a refugee/asylum seeker (1.6 percent), or an internally displaced person ( 2.5 percent). The three subpopulations that were purposively recruited for study participation were communities identified as key populations most affected by HIV in the country: MSM, FSWs, and persons of Haitian descent. Seventeen percent were MSM, defined as those who were assigned male at birth and selfidentified as MSM, gay/homosexual, or bisexual; or who said that they had ever had sex with a man. Nearly one-quarter (24 percent) were FSWs, defined as those assigned female at birth who either self-identified as an FSW, or who said they had exchanged sex for money/goods in the past year. Ten percent were of Haitian descent (Table 2).

Table 2 Membership in specific groups and communities $(\mathrm{N}=891)$

\begin{tabular}{|c|c|}
\hline & $\%(n)$ \\
\hline $\begin{array}{l}\text { Member of a racial, ethnic, or religious } \\
\text { minority }\end{array}$ & $32(283)$ \\
\hline Member of an indigenous/aboriginal group & $<1(4)$ \\
\hline Living with disability (other than HIV) & $7(66)$ \\
\hline Refugee or asylum seeker & $2(14)$ \\
\hline Migrant worker & $10(88)$ \\
\hline Internally displaced person & $3(22)$ \\
\hline Incarcerated/in prison & $3(28)$ \\
\hline $\begin{array}{l}\text { Member of network or support group for } \\
\text { PLHIV }\end{array}$ & $40(352)$ \\
\hline Man who has sex with men ${ }^{+}$ & $17(154)$ \\
\hline Female sex worker ${ }^{\ddagger}$ & $24(216)$ \\
\hline Haitian origin & $10(90)$ \\
\hline
\end{tabular}

'Defined as participants who were assigned male at birth who self-identify as men who have sex with men, gay/homosexual, or bisexual; or who said they ever had sex with man.

${ }^{\ddagger}$ Defined as participants who were assigned female at birth who self-identify as sex workers, or who said they ever exchanged sex for money/goods. 


\section{Stigma Index}

Tables 2 and 3 present disaggregated background characteristics for the total study population, as well as for the three major subpopulations of MSM, FSWs, and Haitian origin PLHIV. Overall, the median age was 38. Fifty-eight percent reported being assigned female at birth, and 42 percent were assigned male. Twenty-six participants described their gender identity as different from the sex they were assigned at birth: 24 ( 3 percent) were transgender women, and two (<1 percent) were transgender men. Median length of time that they had known their status was five years. Overall, more than half (58 percent) were currently in an intimate/sexual relationship, among whom 46 percent reported that their partners also were living with HIV. The proportion of participants who were caring for at least one child ranged from 20 percent among MSM to 81 percent among FSWs (Table 3).

Table 3 Sociodemographic characteristics, by subpopulation

\begin{tabular}{|c|c|c|c|c|}
\hline & $\begin{array}{c}\mathrm{MSM}^{+} \\
(\mathrm{N}=\mathbf{1 5 4})\end{array}$ & $\begin{array}{l}\text { FSWS }^{\ddagger} \\
(\mathrm{N}=216)\end{array}$ & $\begin{array}{l}\text { HAITIAN } \\
\text { ORIGIN } \\
(\mathrm{N}=90)\end{array}$ & $\begin{array}{c}\text { TOTAL } \\
\text { SAMPLE } \\
\text { ( } \mathrm{N}=891 \text { ) }\end{array}$ \\
\hline & \multicolumn{4}{|c|}{$\%(n)$} \\
\hline Age (median years) & 32 & 37 & 39 & 38 \\
\hline \multicolumn{5}{|l|}{ Sex assigned at birth } \\
\hline Female & 0 & $100(216)$ & $57(51)$ & $58(520)$ \\
\hline Male & $100(154)$ & 0 & $43(39)$ & $42(371)$ \\
\hline \multicolumn{5}{|l|}{ Gender identity } \\
\hline Woman & 0 & $100(216)$ & $57(51)$ & $58(518)$ \\
\hline Man & 100 (154) & 0 & 43 (39) & $39(347)$ \\
\hline Transgender woman & 0 & 0 & 0 & $3(24)$ \\
\hline Transgender man & 0 & 0 & 0 & $<1(2)$ \\
\hline $\begin{array}{l}\text { How long HIV-positive status has been } \\
\text { known (median years) }\end{array}$ & 3 & 6 & 4 & 5 \\
\hline Currently in intimate relationship & $44(68)$ & $67(144)$ & $64(58)$ & $58(515)$ \\
\hline Has partner(s) living with HIV & $21(33)$ & $27(58)$ & $39(35)$ & $26(236)$ \\
\hline \multicolumn{5}{|l|}{ Number of children } \\
\hline 0 & $80(123)$ & $19(42)$ & $42(38)$ & $42(378)$ \\
\hline 1 & $11(16)$ & $20(43)$ & $19(17)$ & $18(160)$ \\
\hline $2+$ & $9(4)$ & $61(131)$ & $39(35)$ & $40(352)$ \\
\hline
\end{tabular}

†Defined as participants who were assigned male at birth who self-identify as men who have sex with men, gay/homosexual, or bisexual; or who said they ever had sex with man.

¥Defined as participants who were assigned female at birth who self-identify as sex workers, or who said they ever exchanged sex for money/goods. 


\section{Dominican Republic}

\section{Education, employment, and financial security}

Overall, nearly half (48 percent) of participants had completed secondary education or higher, ranging from 25 percent among those of Haitian origin to 79 percent among MSM. Thirty-eight percent were unemployed, 9 percent worked part-time as an employee, 17 percent were selfemployed or working for others part-time, 25 percent worked full-time as an employee, and 12 percent were self-employed or working for others full-time. Sixty-one percent reported that, in the past 12 months, they were unable to meet basic needs "some of the time." Being unable to meet basic needs was five times more common among FSWs and participants of Haitian origin compared to MSM (Table 4).

Table 4 Education, employment status, and financial security ( $N=891)$

\begin{tabular}{|c|c|c|c|c|}
\hline & $\begin{array}{c}\text { MSMt } \\
(\mathrm{N}=154)\end{array}$ & $\begin{array}{c}\text { FSWS } \\
(\mathrm{N}=216)\end{array}$ & $\begin{array}{l}\text { HAITIAN } \\
\text { ORIGIN } \\
\text { (N=90) }\end{array}$ & $\begin{array}{c}\text { TOTAL } \\
\text { SAMPLE } \\
(\mathrm{N}=\mathbf{8 9 1})\end{array}$ \\
\hline Currently in school & $18(27)$ & $12(25)$ & $7(6)$ & $12(108)$ \\
\hline \multicolumn{5}{|l|}{ Highest level of formal education } \\
\hline Primary or less & $21(33)$ & $54(117)$ & $72(65)$ & $52(463)$ \\
\hline Secondary or higher & $79(121)$ & 46 (99) & $28(25)$ & $48(428)$ \\
\hline \multicolumn{5}{|l|}{ Employment status } \\
\hline Full-time (as an employee) & $45(69)$ & $8(18)$ & $17(15)$ & $25(225)$ \\
\hline Part-time (as an employee) & $12(19)$ & $8(17)$ & $2(2)$ & $9(79)$ \\
\hline Full-time (self-employed or business owner) & $10(16)$ & $8(17)$ & $24(22)$ & $12(103)$ \\
\hline $\begin{array}{l}\text { Casual/part-time work (self-employed/paid by } \\
\text { others) }\end{array}$ & $16(24)$ & $21(46)$ & $17(15)$ & $16(147)$ \\
\hline Unemployed & $17(26)$ & $55(118)$ & $40(36)$ & $38(337)$ \\
\hline \multicolumn{5}{|l|}{ Unable to meet basic needs in past 12 months } \\
\hline Never & $42(64)$ & $15(32)$ & $17(15)$ & $25(226)$ \\
\hline Some of the time & $55(84)$ & $65(140)$ & $64(58)$ & $61(540)$ \\
\hline Most of the time & $4(6)$ & $20(44)$ & 19 (17) & 14 (125) \\
\hline
\end{tabular}

\section{Disclosure}

\section{People who know the interviewee's status}

The most commonly mentioned people who knew participants' status were their children (32 percent), friends (35 percent), spouses/partners (52 percent), and "other relatives" (67 percent). Less common were neighbors (19 percent), employer/boss (10 percent), colleagues (9 percent), community leaders ( 8 percent), teachers ( 2 percent), and classmates ( 2 percent). 


\section{Stigma Index}

\section{Experiences related to disclosure of HIV status}

When asked to state the extent to which they agreed with statements describing their experiences when disclosing their status, 62 percent reported that they agreed or somewhat agreed with the statement, "In general, disclosing your HIV status to people you are close to has been a positive experience." Likewise, 69 percent agreed or somewhat agreed with, "In general, people you are close to were supportive when they first learned about your HIV status." Slightly less than half (47 percent) reported they disagreed with, "In general, disclosing your HIV status has become easier over time."

\section{Experiences with HIV-related discrimination}

Denied a job/income due to HIV status: most common among FSWs

Sixteen percent of FSWs had ever been denied a job/income due to their HIV status. This was reported less frequently among MSM (9 percent) and those of Haitian descent (4 percent).
Overall, the most frequently reported experiences with HIV-related discrimination were having family members make discriminatory remarks because of their HIV status (27 percent), and having people other than family members make such remarks (36 percent). Seventeen percent had been verbally harassed because of their HIV status, and 13 percent reported that they had been refused employment or lost an income source because of their status.

\section{Internalized stigma and resilience}

\section{How HIV status has affected participants}

When asked how their HIV status has affected them in the past 12 months, similar proportions were negatively affected versus positively affected across several indicators: my ability to cope with stress (17 percent negatively affected versus 16 percent positively), my ability to have close relationships (17 percent negatively versus 15 percent positively), and my self-confidence (21 percent for both).
Resilience among FSWs living with HIV About one-fourth of FSWs said their status had positively affected selfconfidence (28 percent) and self-esteem (26 percent). Nearly one-third (31 percent) felt their status had positively affected their achievement of personal and professional goals. 


\section{Dominican Republic}

More participants felt that their status had negatively affected their desire to have children (21 percent negatively affected versus 12 percent positively). In contrast, their HIV status had positively affected their ability to contribute to their community ( 15 percent positively affected, 4 percent negatively affected) as well as their ability to practice a religion/faith as they wanted to (16 percent positively affected versus 3 percent negatively).

\section{Actions and feelings due to internalized stigma around HIV status}

In the past 12 months, due to self-stigma around their HIV status, 18 percent had isolated themselves from family or friends, 16 percent had decided not to have sex, and 17 percent had decided not to apply for jobs. Somewhat less commonly reported behaviors included not seeking social support (12 percent), deciding not to attend social gatherings (11 percent), and deciding not to seek health care (7 percent).

A substantial majority ( 85 percent) agreed that

MSM reported less internalized stigma Due to their HIV status, 6 percent of MSM had decided not to look for work, and 9 percent had isolated themselves from family. In contrast, 17 percent of the overall study population said their status made them not look for work, and 18 percent had isolated themselves from family.

it is difficult to tell people about their HIV status, and that they hide their HIV status from others (69 percent). Fewer reported that being HIVpositive makes them feel dirty ( 20 percent), useless ( 24 percent), guilty (30 percent), or ashamed (34 percent).

\section{Interactions with healthcare services}

\section{HIV testing}

Ninety-one percent of participants $(n=809)$ stated that it was their choice to be tested for HIV, though 6 percent of them felt pressured by others to do so. Among these 809 participants, the most commonly reported reasons for testing were that a provider had recommended it/it was as part of other health services (such as antenatal care or voluntary medical male circumcision) (30 percent), the participant felt at risk of HIV (19 percent), or that the participant felt sick and thought it might be HIV-related (20 percent) (Figure 1).

Nearly three-quarters (73 percent) took six months or less to get tested from the time they first thought about getting tested. Thirty-nine percent reported that fears about how other people would respond to a positive test result made them hesitate to get tested. 


\section{Stigma Index}

Eight percent said they were tested without their knowledge and only found out after the test had been administered. Less than 1 percent reported being forced to test without their consent.

Figure 1 Principal reasons for getting tested, among those who said it was their choice to do so $(n=809)$

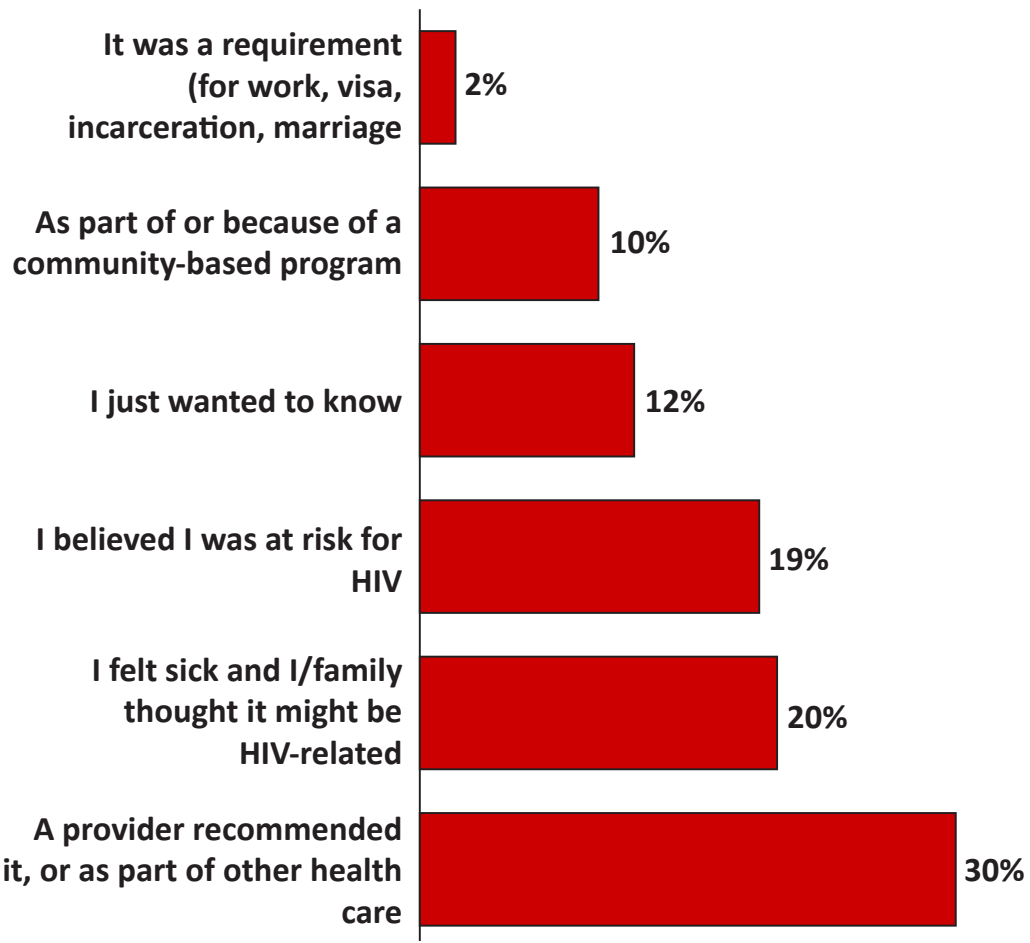

\section{HIV care, treatment, and viral suppression}

When asked if participants had concerns that made them hesitate, delay, or prevent getting HIV care or treatment, 57 percent reported that they worried that their partner, family, or friends would find out about their status. Two-thirds (67 percent) worried that others (not family or friends) would find out their status. Forty-three percent were afraid that health care providers would treat them badly or disclose their status without their consent.
Those of Haitian descent less likely to know they were virally suppressed Overall, half of the 891 participants (56 percent) had been told they had an undetectable viral load in the past 12 months. However, this drops to 33 percent among the 90 participants of Haitian descent.

Of the 888 participants (>99 percent) who had ever received treatment, 23 percent initiated treatment the same day as their diagnosis, and 28 percent within one month of diagnosis. More than one-fourth ( 26 percent) said that more than six months had elapsed before they initiated treatment. 


\section{Dominican Republic}

Ninety-eight percent were currently receiving HIV treatment. About half (56 percent) reported that they had been told they had an undetectable viral load or were virally suppressed in the past 12 months. Five percent had not had a viral load test in the past 12 months, and 15 percent stated that they had received a viral load test and were waiting on results.

\section{Other health conditions}

A large majority of participants described their health at the moment as good (65 percent) or fair (32 percent). Nevertheless, in the past 12 months, 13 percent had been diagnosed with a mental health condition, 7 percent with a sexually transmitted infection, and 3 percent with tuberculosis.

High levels of depression among FSWs and those of Haitian descent Nearly two-thirds of FSWs (61 percent) and Haitian-origin PLHIV (60 percent) had felt down, depressed, or hopeless in the past two weeks.

In the past two weeks, a notable proportion of participants reported experiencing mental health challenges. Nearly half (48 percent) had felt nervous, anxious, or on edge one or more times in that time period; 42 percent had felt unable to stop or control worrying; 42 percent reported little interest or pleasure in doing things; and 52 percent felt down, depressed, or hopeless (Figure 2).

Figure 2 Mental health challenges in past two weeks $(\mathrm{N}=891)$

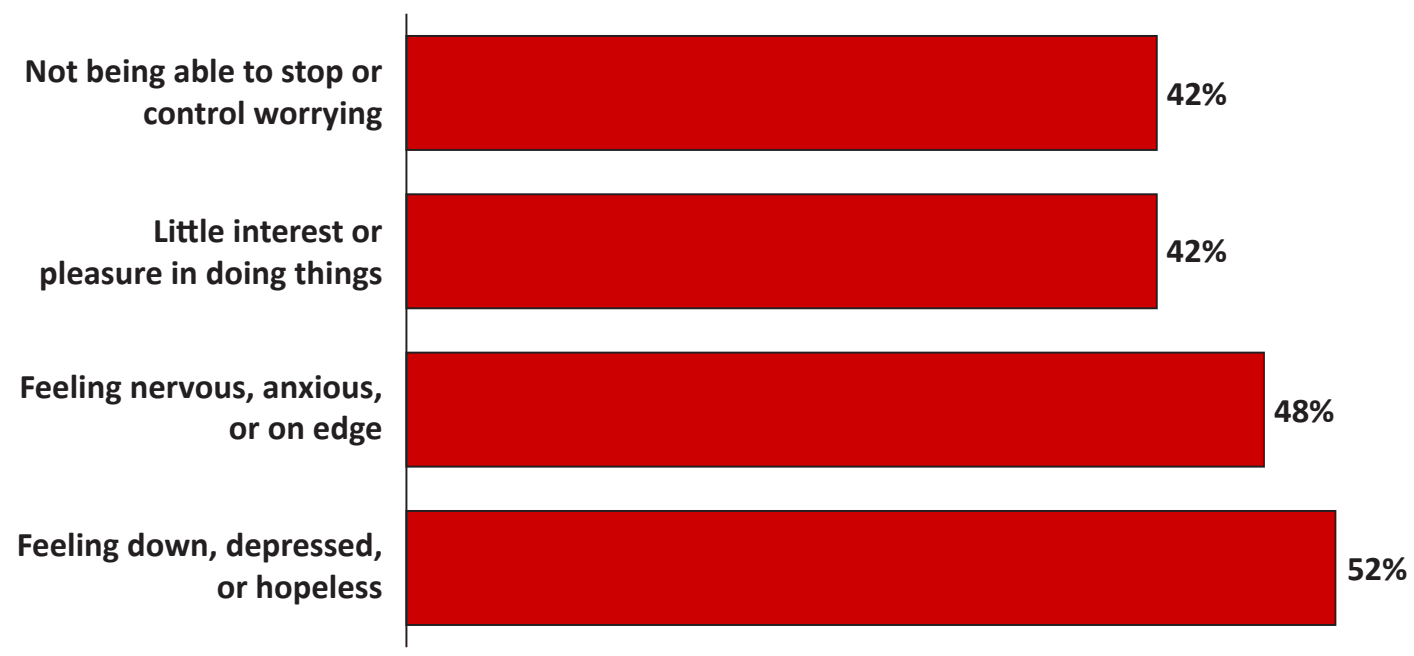

\section{Discriminatory experiences in HIV-specific and non-HIV services}

Sixty-four percent of participants stated that they usually received their regular HIV care and treatment at a government or public facility. The next most frequently mentioned service 


\section{Stigma Index}

delivery site was a nongovernmental organization facility (34 percent). Less than 2 percent went to a private facility or provider. In the past 12 months, the most commonly reported experiences with discrimination in HIV-specific services were having facility staff tell others about their HIV status without their consent ( 7 percent), and being talked badly or gossiped about due to HIV status (7 percent).

Forty-three percent had sought healthcare services for non-HIV health needs in the past 12 months. When seeking care for nonHIV services, the most commonly reported experiences with discrimination were the same as in HIV-specific services, but at higher levels: 14 percent had been talked badly or gossiped about because of HIV status, and 12 percent said facility staff told others about their status

\section{Staff disclosed HIV status without consent, especially among FSWs}

In non-HIV-related services, 18 percent of FSWs said staff disclosed their HIV status without consent in the past year. This was reported less among MSM (9 percent) and PLHIV of Haitian descent (0 percent). without their consent. Other discriminatory experiences that were more common in non-HIV services compared to HIV-specific services were being denied services because of HIV status (4 percent versus 1 percent), verbal abuse due to HIV status (9 percent versus 5 percent), and avoidance of physical contact or taking extra precautions due to HIV status (9 percent versus 4 percent) (Figure 3 ).

Figure 3 Experiences with discrimination in HIV-specific and non-HIV services ${ }^{\dagger}$

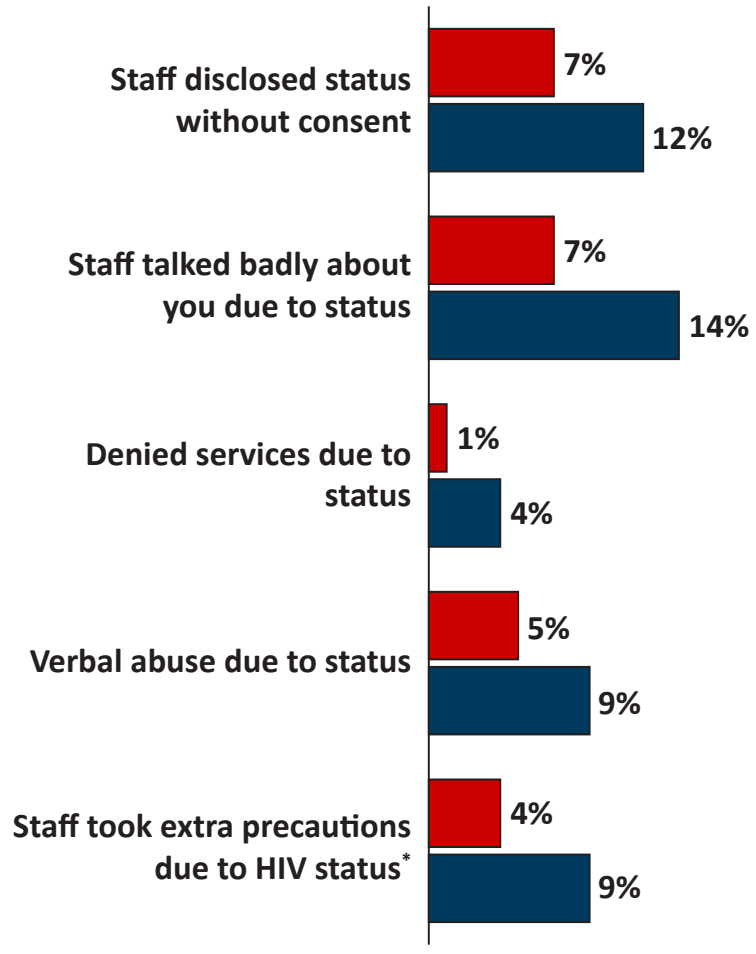

\footnotetext{
'Item-specific sample sizes varied by question, since different numbers of participants reported receiving HIV-specific and non-HIV-specific services in the reporting period. Questions about experiences in HIV-specific services were asked of the entire sample ( $\mathrm{N}=891)$, and questions about experiences in non-HIV-specific services were asked just of those who reported receiving such care in the past year $(n=382)$.

*Such as wearing double gloves, avoiding physical contact.
} 


\section{Dominican Republic}

\section{Sexual and reproductive health}

Few participants ( $<1$ percent) had been denied contraception/family planning services in the past 12 months. However, both women and men reported having a healthcare professional advise them not to have a child in the past 12 months, but this was more common among women ( 8 percent) than men ( 2 percent). Similarly, a much larger proportion of women ( 5 percent) than men ( $<1$ percent) reported being pressured to get sterilized, and 3 percent of women said they were sterilized without their consent (compared to no men).

A notable proportion of women (14 percent) as well as men (12 percent) reported that, in the past 12 months, they had been told that in order to get their HIV treatment, they had to use contraception, or a specific method of contraception. This was much more common among men and women of Haitian descent (36 percent and 41 percent, respectively). Among the 116 participants who had reported this experience, in response to an open-ended follow-up question asking in which geographic area this took place, 38 respondents said Distrito Nacional; 42 said Santo Domingo, Santo Domingo Este, or Santo Domingo Norte; and one each responded Bonao, Puerto Plata, Santiago, La Romana, Dominican Republic, and Haiti. Additionally, in response to this same follow-up question, 22 individuals stated "condoms," implying that this was the method that healthcare providers had advised them to use.

It is worth noting that a roughly equal proportion of men and women stated that a provider had conditioned treatment on use of a specific contraceptive method. Many of these individuals subsequently mentioned that the method in question was condoms. Providers may not have forced them to choose between treatment and contraception per se, but rather, the counseling may have underscored the importance of condom use as a method to prevent HIV transmission. Furthermore, a substantially higher proportion of those of Haitian descent reported this experience, and they had varying levels of Spanish fluency (or in some cases were administered the survey in spontaneously translated Haitian Creole).

A separate set of questions just for women (those assigned female at birth) probed about additional discriminatory experiences related to reproductive health. In the past 12 months, 2 percent reported being advised to terminate a pregnancy solely because of their serostatus, 7 percent reported feeling pressured to use a specific contraceptive method rather than being counseled on a range of available methods, and 5 percent reported feeling pressured to take antiretroviral treatment during pregnancy to reduce vertical HIV transmission, rather than being counseled that this was an option. 


\section{Stigma Index}

\section{Human rights and effecting change}

\section{Abuses of rights}

The most commonly reported rights abuse reported by participants was being forced to get tested for HIV or disclose their status in order to apply for a job or pension plan (8 percent). The next most frequent rights abuse was being forced to have sex when they did not want to (4 percent). For each of the following abuses, less than 3 percent reported ever experiencing: being forced to get tested or disclose status to obtain a visa or apply for residency/citizenship, attend an educational institution, or get a scholarship, health care, or medical insurance; getting arrested or taken to court on a charge related to their status; getting denied a visa or permission to enter a country because of their status; getting denied residency or permission to stay in a country because of their status; and being forced to disclose status publicly without consent.

\section{Taking action on abuses of rights}

\section{Haitian-origin PLHIV had low} awareness of laws protecting them

Only 40 percent of those of Haitian origin knew there were laws in the country to protect PLHIV, compared to two-thirds of the total study population.
Of the 74 people who stated that they had experienced any of the above abuses of rights in the past 12 months, 15 percent said that they tried to do something about the matter (such as file a complaint, contact a government official, or speak out publicly). Among these 11 people who took action, 4 felt that the matter had been dealt with, 6 said nothing happened, and 1 said that the matter was still in the process of being dealt with.

Half of participants had ever provided emotional, financial, or other support to help someone living with HIV deal with stigma and/or discrimination. Nearly 40 percent had challenged or educated someone who was engaging in stigma or discrimination against other PLHIV (34 percent in the past 12 months, 5 percent prior to that).

\section{Stigma and discrimination experienced for reasons other than HIV status}

To elucidate experiences with stigma and discrimination due to reasons other than their HIV status, the Stigma Index 2.0 questionnaire includes a module of questions that is tailored to eight different subpopulations: transgender individuals, MSM, men who identify as gay/ homosexual men, women who have sex with women (WSW), women who identify as lesbian/ gay, bisexual people (both men and women), sex workers (both men and women), and those who use drugs (both men and women). In each module, respondents are asked to state whether they experienced different types of stigma and discrimination explicitly on account of their 


\section{Dominican Republic}

membership in the community in question. Specific definitions for each of these communities are described within each section below.

\section{Experiences of transgender respondents}

Twenty-six participants identified as a gender that differed from the sex they were assigned at birth: 24 transgender women, and 2 transgender men. Many of them reported ever having felt excluded from family activities $(n=9)$, felt that family members made discriminatory remarks or gossiped about them $(n=11)$, or been verbally harassed $(n=12)$ because of their gender identities.

A large majority reported that the following people or groups knew their gender identity: other transgender people or those whose gender identities differ from their assigned sex at birth $(n=23)$, family or other friends $(n=23)$, and others in their communities $(n=22)$. Sixteen of the 26 belonged to a network or support group for transgender people.

\section{Experiences of men who have sex with men}

Seventy-eight men self-identified as MSM and/or had ever had sex with another man, among whom 10 percent reported ever having felt excluded from family activities, and 32 percent had ever felt that family members made discriminatory remarks or gossiped about them because they were MSM. More than one-fifth (21 percent) had ever been verbally harassed because they were MSM.

The most frequently named people who knew that these respondents were MSM were other MSM (68 percent, followed by relatives and friends (48 percent) and other people in the community (31 percent). Fifteen percent belonged to a support group or network for MSM.

\section{Experiences of men who identify as gay/homosexual}

Fifty-sex men identified as gay/homosexual. Their most frequently reported discriminatory experiences were having felt that family members made discriminatory remarks or gossiped about them because they were gay/homosexual (43 percent), and being verbally harassed because they were gay/homosexual (38 percent).

Nearly all of the gay/homosexual respondents reported that family or friends knew they were gay/homosexual (93 percent), and 96 percent said that other gay/homosexual people knew. Eighty-two percent reported that other people knew they were gay/homosexual. Nearly onefourth (23 percent) were members of support groups or networks for gay/homosexual men.

\section{Experiences of women who have sex with women}

Twenty-four women self-identified as women WSW, and/or reported ever having sex with another woman. Four had felt excluded from family activities on account of them being WSW, 


\section{Stigma Index}

and six felt that family members had made discriminatory remarks due to them being WSW. Six also had been blackmailed because they were WSW. Sixteen of the 24 reported that other WSW knew that they were WSW, 10 WSW said that family members or friends knew, and 10 said other community members knew. None were members of support groups or networks for WSW.

\section{Experiences of women who identify as lesbian/gay}

Seven women identified as lesbian/gay, four of whom reported that they had ever felt that family members had made discriminatory remarks based on them being lesbian/gay. Two had been verbally harassed, and two had been blackmailed on account of them being lesbian/gay. All seven reported that family or friends knew they were lesbian/gay, and that other lesbiany/gay women knew. Five of the seven belonged to a support group or network for lesbian/gay women.

\section{Experiences of bisexual respondents}

Fourteen men and women self-identified as bisexual. Seven reported ever feeling that family members had made discriminatory remarks based on them being bisexual, and five had been verbally harassed. Three had been blackmailed for being bisexual. Thirteen said that other bisexual people knew about them being bisexual, 10 said families or friends were aware, and 9 said that others in their community knew. Three of the fourteen were in support groups or networks for bisexual people.

\section{Experiences of sex workers (male and female)}

There were 60 men and 216 women who had ever exchanged sex for money/goods, and/or selfidentified as a sex worker. Nearly one-third (32 percent) had ever felt that family members had made discriminatory remarks based on them being sex workers. Twenty-four percent had ever been verbally harassed on account of them being sex workers. In addition, 17 percent had ever been physically abused because they were sex workers. About half stated that family or friends (55 percent) or others in the community (48 percent) knew that they sold sex. Two-thirds (65 percent) said that other sex workers knew. Twenty-six percent belonged to a support group or network for sex workers.

\section{Experiences of respondents who use drugs}

There were 100 respondents who had ever injected or habitually used drugs (e.g., heroin, cocaine, methamphetamines), and/or who self-identified as a person who uses (or used) drugs. Half said they had ever felt that family members had made discriminatory remarks based on them using drugs. Thirty-four percent had ever felt excluded from family activities on account of them using drugs. Twenty percent had been blackmailed due to their drug use. Eighty percent did not belong to a support group or network for people who use drugs. 


\section{Dominican Republic}

\section{IMPLICATIONS AND RECOMMENDATIONS}

The DR was the first country to implement the original Stigma Index in 2008, and one decade later, our results from Stigma Index 2.0 describe ongoing challenges that PLHIV confront regarding stigma and discrimination in the country. These include ongoing discomfort with disclosing HIV status, persistent internalized stigma, and discrimination related to HIV status as well as to membership in marginalized communities (such as MSM, sex workers, or people who inject drugs). The study teams from REDOVIH and ASOLSIDA expressed satisfaction with how the study was conducted, especially in terms of empowering PLHIV through the implementation of the Stigma Index. In some cases, interviewers provided spontaneous peer support and counseling to interviewees, explaining the importance of treatment adherence, educating respondents about their rights, and helping them identify symptoms of opportunistic infections. The study was both informative and humanizing for interviewer and interviewee alike. The following section summarizes key findings as well as specific comments and recommendations made by community members at the June 2019 Santo Domingo research dissemination meeting.

\section{PLHIV need education about rights regarding employment discrimination}

A relatively small proportion of participants (13 percent) reported employment discrimination due to their HIV status, and just 2 percent said they got tested as a requirement of employment. Nevertheless, considering the very high levels of unemployment and financial insecurity among participants, community members at the dissemination event voiced the view that both employers as well as PLHIV themselves needed to be sensitized about the labor rights of PLHIV. This need is particularly salient among those of Haitian origin, who exhibited lower awareness of the existence of laws that protect PLHIV rights and were of lower economic status.

\section{Disclosure is an ongoing challenge, particularly among MSM and those of Haitian descent}

Most participants had disclosed their status to spouses/partners or other relatives, and the majority found it to be a positive experience to disclose their status to people with whom they were close. Nevertheless, most did not feel that disclosure has become easier over time, a sentiment that was most prevalent among Haitian-origin participants and MSM. Clinical and social services that support disclosure are needed, particularly for marginalized communities. In addition, community members emphasized that public education campaigns are necessary to increase knowledge in the general population about what HIV is, and how it is and is not 


\section{Stigma Index}

transmitted. Such efforts will help to confront and mitigate HIV-related stigma that fosters an environment in which PLHIV feel they cannot disclose.

\section{Viral suppression gap suggests need for improved counseling and treatment literacy}

The finding that one-half had not been told that they were virally suppressed in the past year is concerning, particularly considering that nearly all participants were on treatment and, ostensibly, having regular contact with the health system. Community members' recommendations for closing this viral suppression gap were: improve treatment literacy through counseling, ensuring that PLHIV understand what it means to be virally suppressed, how risk of sexual transmission of HIV is eliminated when viral suppression is achieved, and that it is important to adhere to treatment even when virally suppressed. Community members remarked that there is a common misperception that viral suppression means one can abandon treatment, and they emphasized the importance of correcting this myth.

\section{Mental health issues require specialized psychosocial services}

Mental health challenges were common among respondents, with more than half of participants expressing sentiments such as hopelessness, anxiety, and uncontrollable worrying in the past two weeks. Community members recommended that counseling and support for PLHIV include strengthened psychosocial services, or referral to such specialized mental health care, when necessary.

\section{Healthcare providers and staff need education and sensitization to reduce stigma and discrimination, particularly in non-HIV-services}

In health care settings, a highlighted finding was that experiences with stigma and discrimination were more common in non-HIV-related services, compared to HIV-specific services. Participants at the dissemination event highlighted that there remains a tremendous need to educate providers across specialties of the rights of PLHIV, and how to provide respectful, nonjudgmental care. In addition, they noted the importance of educating PLHIV about their rights and ensuring there are mechanisms in place that allow them to anonymously report abuses experienced in healthcare settings. Evidence-based interventions to reduce provider stigma and discrimination should be implemented to improve PLHIV experiences in health care settings. 


\section{Dominican Republic}

\section{Peer education and community mobilization should focus on improving awareness of laws supporting PLHIV rights}

PLHIV advocates and community members stressed the need to fortify peer education and community mobilization efforts to improve awareness of existing laws in the country protecting the rights of PLHIV. Awareness of PLHIV rights was particularly low among respondents of Haitian descent, suggesting that these efforts need to make specific, tailored inroads into these communities.

\section{Different communities have diverse needs, which require customized responses}

The background characteristics of participants varied widely across communities, with those of Haitian descent of lower socioeconomic status compared to the overall study population, and compared to MSM and FSWs. Employment-related discrimination was reported most frequently among FSWs, for whom disclosure of HIV status could mean losing clients, for instance. Although not identified as a key population in most HIV programs in the DR, 11 percent of respondents used drugs, half of whom felt that family members made disparaging remarks about them due to their drug use, but just 20 percent of whom belonged to a support group or network for those who use drugs. 


\section{Stigma Index}

\section{LIMITATIONS AND CHALLENGES}

\section{Small sample sizes for some communities, limited generalizability}

The recruitment methodology for this study relied largely on reaching out to individuals who were already connected to services, support networks, or peers. Thus, our findings cannot be extrapolated to those who are less accessible (such as those who are not in treatment or who do not access any HIV-related services or peer support). In addition, the numbers of transgender people and bisexual individuals were small, limiting our ability to conduct meaningful analysis for these communities.

\section{Potential translation challenges, particularly for respondents of Haitian descent}

As discussed previously, some findings raise questions about whether some nuance or meaning of the original English questions may have been distorted in the Spanish translation. Future implementation of the Stigma Index 2.0 in Spanish-speaking contexts should consider first conducting a back-translation of the Spanish version to English to detect other such instances of potential confusion in translation, so that the wording can be refined accordingly. In the future, considering how the Haitian-origin community is particularly affected by HIV in the DR, translation of the Stigma Index 2.0 into Haitian Creole would be a worthwhile investment. 


\section{Dominican Republic}

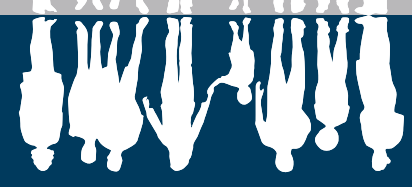

\section{CONCLUSION}

Implementation of Stigma Index 2.0 in the DR was led by PLHIV themselves, true to the philosophy and intent of this participatory methodology. These findings build on and update results from the original Stigma Index fielded in the DR more than a decade ago. With the inclusion of modules on mental health, expanded content on experiences in health care settings, and intentional recruitment of MSM, FSWs, and PLHIV of Haitian descent, Stigma Index 2.0 sheds light on ongoing challenges and opportunities regarding HIV-related stigma in the DR. 


\section{Stigma Index}

\section{REFERENCES}

Cáceres, F. 2009. República Dominicana: estigma y discriminación en personas que viven con el VIH. Santo Domingo: Asociación Dominicana Pro Bienestar de la Familia (Profamilia).

Centro de Estudios Sociales y Demográficos (CESDEM) \& ICF International. 2014. Encuesta Demográfica y de Salud 2013. Santo Domingo, Dominican Republic: CESDEM \& ICF International.

Valdez, C, E. Barillas, I. Cepeda, and L. Ledesma. 2017. “Diagnóstico de la Situación de Estigma y Discriminación hacia Poblaciones Claves, en 15 Servicios de Atención Integral al VIH (SAI) priorizados, en República Dominicana." Presented to the Global Fund of the National Council on HIV and AIDS (CONAVIHSIDA), Santo Domingo, Dominican Republic. 



\section{DISCLAIMER}

The People Living with HIV Stigma Index is designed as a research tool by which people living with HIV capture data on their experiences and perceptions regarding stigma and discrimination.

In this regard, the results can be said to comprise a snapshot of the level of HIV-related stigma and discrimination in a certain place and time. Through its implementation, the tool also serves to educate and empower people living with HIV on human rights related to HIV.

Survey questions therefore focus on experiences and perceptions and do not represent factual investigations, with follow up questions, into particular allegations, incidents or events nor are the answers to the questions subject to independent verification. As research participants, interviewees have a right to anonymity and to confidentiality regarding their responses.

In addition to the empowerment function, appropriate uses of the data are for advocacy and to inform stigma/ discrimination reduction programming and policy responses in the national response to HIV as well as contribute to what we know (from the lived experience of PLHIV) about HIV-related stigma globally. 